\title{
Clinical and microbiological characteristics of non-tuberculous mycobacteria diseases in Singapore with a focus on pulmonary disease, 2012-2016
}

\author{
Zoe Xiaozhu Zhang ${ }^{1,2^{*}}$, Benjamin Pei Zhi Cherng ${ }^{3}$, Li-Hwei Sng ${ }^{4}$ and Yen Ee Tan ${ }^{4}$
}

\begin{abstract}
Background: Information on non-tuberculosis mycobacterial (NTM) diseases remains limited in Singapore and other Southeast Asian countries. This study aimed to delineate epidemiological and clinical features of pulmonary NTM disease.

Methods: A retrospective review was performed on all NTM isolates identified in Singapore General Hospital from 2012 to 2016 using the 2007 ATS/IDSA diagnostic criteria.

Results: A total of 2026 NTM isolates from 852 patients were identified. M. abscessus-chelonae group (1010, 49.9\%) was the most commonly isolated and implicated in pulmonary NTM disease. Pulmonary cases $(352,76 \%)$ had the highest prevalence among patients diagnosed with NTM diseases $(465 / 852,54.6 \%)$ with no gender difference. Male patients were older (68.5 years, $P=0.014$ ) with a higher incidence of chronic obstructive pulmonary disease (COPD) $(23.6 \%$, $P<0.001)$ and recurrent cough with phlegm production $(51.6 \%, P=0.035)$. In contrast, more female patients had bronchiectasis $(50 \%, P<0.001)$ and haemoptysis $(37.6 \%, P=0.042)$. Age and COPD were associated with multiple NTM species isolation per patient.

Conclusions: M. abscessus-chelonae group was the commonest NTM species isolated in Singapore. Pulmonary NTM infection has the highest frequency with male and female patients associated with a higher incidence of COPD and bronchiectasis respectively. Age and COPD were associated with multiple NTM species isolation per patient.
\end{abstract}

Keywords: Non-tuberculous mycobacteria, Mycobacterium abscessus, Singapore

\section{Background}

Non-tuberculous mycobacteria (NTM) has been increasingly implicated in a broad range of infectious diseases worldwide [1-4]. These environmental microbes are found primarily in water and soil. Possible route of transmission includes direct exposure to aerosolized water or soil containing NTM species [2-5]. The interaction between host immune system and the pathogenicity of the organisms plays a key role in disease susceptibility [6].

\footnotetext{
* Correspondence: zoe_zhang_xz@ttsh.com.sg

'Department of Epidemiology, Medical Board, Singapore General Hospital, Singapore, Singapore

${ }^{2}$ Department of Clinical Epidemiology, Office of Clinical Epidemiology, Analytics, and kNowledge (OCEAN), Tan Tock Seng Hospital, Singapore, Singapore

Full list of author information is available at the end of the article
}

Well-defined host risk factors include advanced age, male gender, slender and older Caucasian women, immune defects, structural pulmonary diseases, alpha1-antitrypsin deficiency [7-11]. Urban living, especially in wet area with dense population, also increases the susceptibility to NTM infections $[12,13]$. Other predisposing factors include low body-mass index, skeletal abnormalities and gastroesophageal reflux [11, 14].

Pulmonary, lymphadenitis, skin/soft tissue and dissemination are the four major clinical manifestations of NTM infections. Pulmonary NTM is the commonest clinical syndrome $[15,16]$ and it is associated with significant morbidity among older adults [7, 17]. Structural pulmonary diseases such as cystic fibrosis, chronic obstructive pulmonary disease (COPD) bronchiectasis, and tuberculosis

(c) The Author(s). 2019 Open Access This article is distributed under the terms of the Creative Commons Attribution 4.0 International License (http://creativecommons.org/licenses/by/4.0/), which permits unrestricted use, distribution, and reproduction in any medium, provided you give appropriate credit to the original author(s) and the source, provide a link to the Creative Commons license, and indicate if changes were made. The Creative Commons Public Domain Dedication waiver (http://creativecommons.org/publicdomain/zero/1.0/) applies to the data made available in this article, unless otherwise stated. 
(TB) predispose individuals to NTM lung infections. In the United States (US), an estimation of 86,000 NTM pulmonary cases were reported in 2010 with the prevalence of 8.6 per 100,000 [18], and the number was growing by approximately $8 \%$ every year [14]. In Canada, the prevalence of NTM pulmonary disease was estimated to be 9.8 per 100,000 in 2010 [19]. Asians and Pacific Islanders appear to be more susceptible to NTM diseases [14]. Several studies have reported the increasing number of annual NTM isolates and the significant clinical relevance [20-22]. In Korea, the incidence of pulmonary NTM disease has doubled in 2015 compared to the number in 2009 [23, 24]. Japan revealed that NTM disease has reached 14.7 cases per 100, 000 people-years [25] . Pulmonary NTM disease has been described common in Taiwan, with the average incidence rate of 46.0 episodes per 100,000 hospital-based patient-years from 2010 to 2014 [26]. The epidemiology of NTM pulmonary disease differs in various geographical regions. The data remains limited in Southeast Asian countries including Singapore.

Singapore is a highly urbanized city-state with a tropical climate. It is the world's third most densely populated country with a total population of 5.6 million. The percentage of the population aged $\geq 65$ years is over $10 \%$ and is projected to grow to nearly $20 \%$ by 2030 [27]. In addition, a large proportion of residents aged over 50 years have a history of TB as TB was prevalent in Singapore until the 1970s [28]. Collectively, high population density, a wet tropical urban environment, and a large aging population with history of TB make the residents of Singapore particularly susceptible to NTM diseases. In this study, we evaluated the epidemiological and clinical characteristics of NTM diseases in Singapore, with an emphasis on pulmonary infection.

\section{Methods}

\section{Study setting and study subjects}

Singapore General Hospital (SGH) is a 1700-bedder tertiary hospital located within the Outram Campus in Singapore with 5 other National Specialty Centres, facilitating a comprehensive range of medical services for over 1 million patients annually. SGH CTBL is one of the two centralized laboratories accredited for mycobacterial testing in Singapore and is responsible for about $80 \%$ of the country's mycobacterial culture testing volumes. All NTM isolates identified in SGH CTBL from 1st January 2012 to 31st December 2016 were included in the study. These were speciated by a combination of methods including high-performance liquid chromatography (HPLC; Beckman Instruments, USA), INNO-LiPA Mycobacteria v2 (Innogenetics, Belgium) and/or DNA probes (AccuProbes; Gen-Probe, USA) and correlated with the colonial morphology, pigmentation and growth rate. For cases with multiple isolates of one or more species, only the first isolate of the same species was included for analysis. M. gordonae, a well-known environmental contaminant, was excluded from the analysis [29-31]. Isolates were cultivated from various anatomical sites which included pulmonary source (sputum, bronchoalveolar lavage (BAL), lung biopsy, endotracheal tube aspirate (ETTA) and pleural fluid) and extrapulmonary sources such as skin and soft tissue, blood, lymph node and other sterile sites.

\section{Data collection}

Medical records of included cases were reviewed from the electronic medical record system by trained research coordinators with nursing or medical background. The following information were collected: 1) Patients' demographic information, 2) medical comorbidities, 3) clinical presentations, 4) radiology findings of nodular, cavitary opacities or bronchiectasis on chest X-ray (CXR); or bronchiectasis with multiple small nodules on high resolution computed tomography (HRCT) scan, and 5) microbiology results. In addition, history of tuberculosis, body-mass index (BMI) were also recorded.

NTM diseases were defined using the criteria proposed by 2007 American Thoracic Society and the infectious Diseases Society of America (ATS/IDSA) and were further categorized as pulmonary disease, skin/soft tissue disease, disseminated disease (blood/other sterile sites infection), lymphadenitis. NTM pulmonary disease was defined when patients had a combination of clinical, radiological, and microbiological features [32].

\section{Statistical analysis}

Categorical variables were expressed as counts (percentage). Differences in frequencies were compared using a $\mathrm{X}^{2}$ test or Fisher's exact test. Continuous variables were expressed as median with 25-75th interquartile range (IQR), and the difference was assessed using Mann-Whitney- $U$ test. Univariate analysis was performed to assess the association between risk factors and multi-species infection, and the results were presented as odds ratios (ORs) with 95\% confidence intervals (95\% CIs). All the analyses were done using STATA, version 13 for Windows.

\section{Results}

Specimen source and NTM species distribution

A total of 2026 NTM isolates from 852 patients were identified during the 5 -year study period. The specimen types and detected species were shown in Tables 1 and 2 respectively. Respiratory specimens were predominant (1777, 87.7\%). The top four prevalent species were $M$. abscessus-chelonae group (1010, 49.9\%), M. fortuitum group (345, 17\%), M. avium complex (MAC) (309, $15.3 \%)$, and M. kansasii (233, 11.5\%). 
Table 1 Sources of the specimens ( $N=2026)$

\begin{tabular}{lll}
\hline Specimen source & Sub-total N (\%) & Total N (\%) \\
\hline Pulmonary & $1519(75)$ & $1777(87.7 \%)$ \\
Sputum & $195(9.6)$ & \\
Broncho alveolar lavage & $39(1.9)$ & \\
Lung biopsy & $12(0.6)$ & $249(12.3 \%)$ \\
ETT aspirate & $12(0.6)$ & \\
Pleural fluid & \\
Extra-pulmonary & $96(4.7)$ & \\
Skin/soft tissue & $138(6.8)$ & \\
Blood/sterile sites & $15(0.74)$ & \\
Lymph node &
\end{tabular}

Note: the data was presented as number (\%) otherwise specified

\section{NTM diseases}

The study flowchart is shown in Fig. 1. Due to single sputum culture or the absence of characterized radiological changes as described in ATS/IDSA guideline, 387 patients with NTM isolate(s) from respiratory specimens (45.3\%) were excluded from further analysis. Among the rest 465 patients (54.6\%) who fulfilled ATS/IDSA diagnostic criteria, 460 patients had NTM isolated from one source, whereas 5 other patients had NTM isolated from $\geq 2$ sources. The detailed disease distribution was illustrated in Fig. 2. Comorbidities of patients with NTM isolates from blood/other sterile sites mainly consisted of HIV/ intro-venous drug abuse $(11 / 49,22.4 \%)$, malignancies (10/

Table 2 NTM species distribution of all the investigated isolates $(N=2026)$

\begin{tabular}{|c|c|}
\hline Organism & No. of counts (\%) \\
\hline M. abscessus-chelonae group & $1010(49.9)$ \\
\hline M. fortuitum group & $345(17.0)$ \\
\hline M. avium complex & $313(15.4)$ \\
\hline M. kansasii & $233(11.5)$ \\
\hline M. haemophilum & $41(2.0)$ \\
\hline M. scrofulaceum & $22(1.1)$ \\
\hline M. mucogenicum & $16(0.8)$ \\
\hline M. lentiflavum & $14(0.7)$ \\
\hline M. triplex & $10(0.5)$ \\
\hline M. interjectum & $7(0.3)$ \\
\hline M. simiae & $7(0.3)$ \\
\hline M. marinum & $5(0.2)$ \\
\hline M. terrae complex & $5(0.2)$ \\
\hline M. szulgai & $4(0.2)$ \\
\hline M. genavense & $2(0.1)$ \\
\hline M. neoaurum & $2(0.1)$ \\
\hline M. celatum & $1(0.05)$ \\
\hline
\end{tabular}

Note: the data was presented as number (\%) otherwise specified

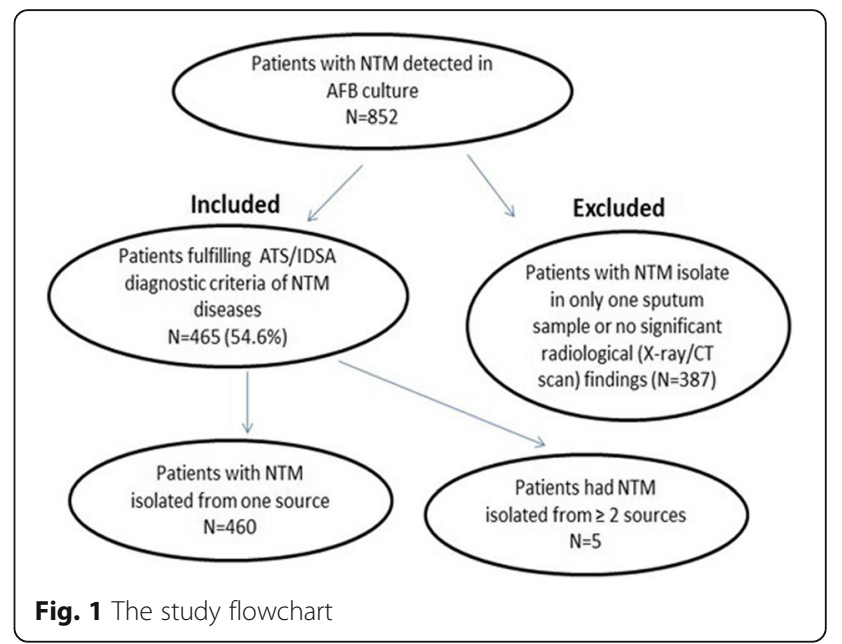

$49,20.4 \%)$, end stage renal failure $(10 / 49,20.4 \%)$, and ischemia heart disease /chronic heart failure (9/49, 18.4\%). The species and isolates distribution of patients with NTM diseases were listed in Tables 3 and 4.

\section{NTM pulmonary diseases Demographic information and clinical features}

Of the 744 patients with NTM isolates from respiratory specimens, 352 patients (47.3\%) met ATS/IDSA case criteria for pulmonary NTM disease. $M$. abscessus-chelonae group $(197,56 \%)$ was the predominately pathogenic species. The median age of the patients was 67 years (Table 4). Malignant diseases, COPD and bronchiectasis were the major comorbidities. Male patients were older, and more often had COPD; whereas female patients more often had bronchiectasis (Table 5).

\section{Factors associated with multiple NTM species detection} Of the 352 patients with pulmonary NTM infection, 106 patients had $\geq 2$ NTM species isolated either in the same setting (41/106) or at different time point (65/106). There were no species matching-pattern or sequential order observed. However, univariate analysis revealed

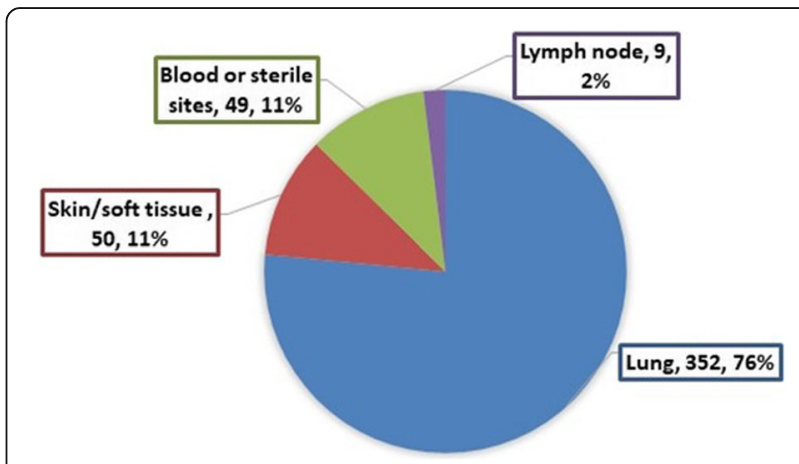

Fig. 2 The distribution of NTM diseases among the study subjects 
Table 3 NTM species distribution among the patients diagnosed with NTM diseases $(N=460)$

\begin{tabular}{|c|c|c|c|c|c|}
\hline Species & $\begin{array}{l}\text { Pulmonary } \\
N=352(\%)\end{array}$ & Skin/soft tissue $N=50(\%)$ & $\begin{array}{l}\text { Blood/ other sterile sites } \\
N=49(\%)\end{array}$ & $\begin{array}{l}\text { Lymph node } \\
N=9(\%)\end{array}$ & $\begin{array}{l}\text { Total } \\
N=460(\%)\end{array}$ \\
\hline M. chelonae -M. abscessus group & $197(56)$ & $25(50)$ & $16(32.7)$ & $6(66.7)$ & $244(53)$ \\
\hline M. avium complex (MAC) & $99(28.1)$ & $4(8)$ & $14(28.6)$ & $1(11.1)$ & $118(25.7)$ \\
\hline M. fortuitum species group & $91(25.9)$ & $7(14)$ & 15 (30.6) & 0 & $113(24.6)$ \\
\hline M. kansasii & $71(20.2)$ & & $1(2.0)$ & $1(11.1)$ & $73(15.9)$ \\
\hline M. scrofulaceum & $8(2.3)$ & & & & $8(1.7)$ \\
\hline M. mucogenicum & $6(1.7)$ & & $2(4.1)$ & & $8(1.7)$ \\
\hline M. lentiflavum & $3(0.9)$ & & & & $3(0.7)$ \\
\hline M. szulgai & $2(0.6)$ & & & & $2(0.4)$ \\
\hline M. interjectum & $1(0.3)$ & & & & $1(0.2)$ \\
\hline M. simiae & $1(0.3)$ & $1(2.0)$ & & & $2(0.4)$ \\
\hline M. triplex & $1(0.3)$ & & & & $1(0.2)$ \\
\hline M. genavense & & & & $1(11.1)$ & $1(0.2)$ \\
\hline M. haemophilum & & $10(20)$ & $2(4.1)$ & & $12(2.6)$ \\
\hline M. marinum & & $3(6.0)$ & & & $3(0.6)$ \\
\hline M. neoaurum & & & $2(4.1)$ & & $2(0.4)$ \\
\hline M. terrae complex & & $1(2.0)$ & & & $1(0.2)$ \\
\hline
\end{tabular}

Note: the data was presented as number (\%) otherwise specified

that age $\geq 65$ years and COPD were associated with multiple NTM species isolation with OR of 1.7 and 2.2 respectively (Table 6).

\section{Discussion}

In this study, we evaluated the clinical relevance of all NTM isolates cultured in CTBL in SGH from 2011 to 2015. We found that $54.6 \%$ of the patients with NTM isolates met ATS/IDSA diagnostic criteria of NTM diseases. Nearly half of the patients with pulmonary isolates may have active NTM lung infections, significantly higher than the rates reported in Hong Kong and Korea (47\% vs. $20-25 \%)$ [20, 33]. This may suggest that pulmonary NTM isolates were more likely associated with pulmonary NTM infection rather than colonization among the patients in Singapore.

The distribution of NTM species varies geographically. M. avium complex (MAC) are the most commonly isolated and involved in pulmonary NTM infections in the US, Canada, Japan, Korea, Hong Kong and Taiwan [22, 32-40]. In contrast, our study showed that $M$. abscessus-chelonae group was the most prevalent and most implicated in pulmonary NTM disease among the patients in Singapore. Here we grouped M. chelonae and M. abscessus together as the two species could not be reliably differentiated by the line-probe assay (INNO-LiPA). However, an in-house review of isolates that were tested by both INNO-LiPA and HPLC revealed that all $M$. abscessus-chelonae group identified by INNO-LiPA were confirmed to be $M$. abscessus by HPLC method (Data not published). In view of this and the fact that $M$. chelonae rarely causes chronic lung disease [32], $M$. abscessus was likely to be the main pathogenic species in pulmonary NTM infections in our patient cohort. This observation was in line with another study in Singapore and a study conducted in southernmost region of Japan with subtropical climate [41, 42]. We postulated the higher prevalence of $M$. abscessus in our setting may be due to the tropical climate, densely populated urban living and history of TB infection. However, more studies are required to prove these hypotheses.

M. abscessues subsp. abscessus is often associated with poor clinical prognosis because of the possession of a functional erm [41] gene that confers macrolide resistance. M. abscessus subsp. massiliense, on the other hand, generally remains susceptible to macrolide due to the truncation of erm gene [43, 44]. Subspeciation of $M$. abscessus complex may provide important guidance in the clinical management of $M$. abscessus complex infection. Unfortunately, this data is not available during the study period as the test was not performed routinely. In addition, macrolide resistance is not routinely tested. If clinically indicated, the clinicians will order susceptibility testing for $M$ abscessus and the microbroth dilution plate will be kept for a total of 14 days to detect inducible macrolide resistance. This is in accordance to CLSI (Clinical and Laboratory Standards Institute) M24-A2 [45].

In this study, M. fortuitum species group was detected in about $25 \%$ of the patients with pulmonary NTM diseases. The role of $M$. fortuitum group as the causative agent in infection can be controversial because it could 
Table 4 Baseline characteristics of the patients with pulmonary NTM disease $(N=352)$

\begin{tabular}{|c|c|}
\hline Characteristics & No. of subjects (\%) \\
\hline Male, No. (\%) & $182(51.7)$ \\
\hline Median Age (IQR) (years) & $67(58-74)$ \\
\hline Median BMI (IQR) & $18.8(16.2-21.5)$ \\
\hline \multicolumn{2}{|l|}{ Ethnic groups } \\
\hline Chinese & $306(86.9)$ \\
\hline Malay & $19(5.4)$ \\
\hline Indian & $11(3.1)$ \\
\hline Others & $16(4.5)$ \\
\hline \multicolumn{2}{|l|}{ Coexisting illness } \\
\hline Transplant & $7(2.0)$ \\
\hline HIV & $13(3.7)$ \\
\hline Ischemia heart disease & $42(11.9)$ \\
\hline Congestive heart failure & $7(2.0)$ \\
\hline Malignant diseases & $96(27.3)$ \\
\hline Renal disease & $11(3.1)$ \\
\hline Liver disease & $9(2.6)$ \\
\hline Diabetes mellitus & $43(12.2)$ \\
\hline Cardiovascular disease & $42(11.9)$ \\
\hline COPD & $46(13.1)$ \\
\hline Bronchiectasis & $128(36.4)$ \\
\hline Asthma history & $14(4.0)$ \\
\hline TB history & $97(27.6)$ \\
\hline Cerebrovascular disease & $14(4.0)$ \\
\hline \multicolumn{2}{|l|}{ Clinical presentations } \\
\hline Cough & $261(74.1)$ \\
\hline Recurrent cough with phlegm production & $160(45.5)$ \\
\hline Haemoptysis & $114(32.4)$ \\
\hline Weight loss & $28(8.0)$ \\
\hline Night sweat & $7(2.0)$ \\
\hline Laboratory Investigations & $28(8.0)$ \\
\hline AFB smear $(+)$ & $113(32.1)$ \\
\hline Blood culture $(+)$ & $3(0.9)$ \\
\hline Sputum culture (+) & $30(8.5)$ \\
\hline \multicolumn{2}{|l|}{ Radiological findings } \\
\hline \multicolumn{2}{|l|}{ Chest X-ray $(N=330)$} \\
\hline Fibrocavitary & $25(7.6)$ \\
\hline Nodular bronchiectasis & $144(43.6)$ \\
\hline \multicolumn{2}{|l|}{ CT scan $(N=260)$} \\
\hline Fibrocavitary & $27(10.4)$ \\
\hline Nodular bronchiectasis & $255(98.1)$ \\
\hline
\end{tabular}

Note: the data was presented as number (\%) otherwise specified; $B M I$ body mass index, COPD Chronic pulmonary obstructive disease, $T B$ tuberculosis, HIV Human immunodeficiency virus be colonization or transient infection [46, 47]. However, some studies have reported that $M$. fortuitum is the pathogen implicated in pulmonary NTM infection and skin and bone/joint infection as well [32, 48-50]. Therefore, it should always be correlated with the clinical findings to determine its clinical significance and management. In addition, $M$. kansasii is a virulent but an uncommon species in Asia. However, it was surprisingly the fourth commonest NTM species implicated in pulmonary infection among the patients in Singapore [20, $22,33]$. Hence, it is important to understand the local epidemiology before applying guidelines elsewhere.

Structural lung diseases predispose people to pulmonary NTM infection $[9,14,34,51-56]$. In this study, about $50 \%$ of patients with pulmonary NTM infection had COPD or bronchiectasis. Male patients had a higher incidence of COPD and more often presented with recurring cough and sputum production; in contrast, female patients had bronchiectasis and haemoptysis more frequently. These distinct features were consistent with the findings observed in other studies [34, 57, 58]. Pulmonary tuberculosis is another important pathophysiological process associated with severe pulmonary structural damage. A history of tuberculosis is a distinct characteristic among Asian patients with pulmonary NTM diseases [59]. In this study, one-third of the patients with pulmonary NTM infections had prior TB, which was not surprising as the incidence of $\mathrm{TB}$ in Singapore was about 307 cases per 100,000 population in 1960 [28]. By the way, the prevalence of pulmonary NTM disease was similar in male and female patients. Both male and female patients had slim figure with BMI close to the lower end of the normal range $\left(18.9 \mathrm{~kg} / \mathrm{m}^{2}\right.$ and $18.6 \mathrm{~kg} / \mathrm{m}^{2}$ respectively).

Isolation of multiple NTM species in the same setting or over a period of time is another feature of NTM lung infection and the underlying reason is unclear [60-62]. In this study, around $30 \%$ of the pulmonary NTM patients had $\geq 2$ species identified. As clinical treatment data was not gathered in current study, we cannot tell if was related to clinical treatment as suggested by Lee et al. [63] However, we found that age $\geq 65$ years and COPD were significantly associated with multispecies isolation with OR of 1.7 and 2.2 respectively. Chronic inflammation and remodelling of airways in COPD may play a role in the increased susceptibility to NTM infection.

This study has several limitations. Firstly, this is a retrospective study and the collected data may be incomplete. Secondly, the study was conducted in a single hospital not all adult tertiary-care hospitals in Singapore. Nonetheless, as patients from all over Singapore can seek care from any tertiary-care hospital in the country, any selection bias was likely to be minimal. Thirdly, there may be an underestimation in the prevalence of 
Table 5 Comparison between male and female patients with NTM lung disease $(N=352)$

\begin{tabular}{|c|c|c|c|}
\hline Characteristics & Male $(N=182)$ & Female $(N=170)$ & $P$ value \\
\hline Median Age (25 th-75th IQR) (years) & $68.5(61-76)$ & $66(56-73)$ & $0.014^{*}$ \\
\hline Median BMI (25th-75th IQR) & $18.9(16.2-22.3)$ & $18.6(16.1-21.3)$ & 0.711 \\
\hline \multicolumn{4}{|l|}{ Coexisting illnesses No. (\%) } \\
\hline HIV & $11(6.0)$ & $2(1.2)$ & $0.021^{*}$ \\
\hline Ischemia heart disease & $34(18.7)$ & $8(4.7)$ & $<0.001^{*}$ \\
\hline Neoplastic disease & $48(26.4)$ & $48(28.2)$ & 0.7 \\
\hline Diabetes mellitus & $29(15.9)$ & $14(8.2)$ & $0.028^{*}$ \\
\hline COPD & $43(23.6)$ & $3(1.8)$ & $<0.001^{*}$ \\
\hline Bronchiectasis & $43(23.6)$ & $85(50.0)$ & $<0.001^{*}$ \\
\hline TB history & $64(35.2)$ & $33(19.7)$ & $0.001^{*}$ \\
\hline \multicolumn{4}{|l|}{ Clinical symptoms } \\
\hline Cough & $141(77.5)$ & $120(70.6)$ & 0.14 \\
\hline Recurrent cough with phlegm & $94(51.6)$ & $66(38.8)$ & $0.035^{*}$ \\
\hline Haemoptysis & $50(27.5)$ & $64(37.6)$ & $0.042^{*}$ \\
\hline Weight loss & $38(20.9)$ & $33(19.4)$ & 0.73 \\
\hline Chest pain & $17(9.3)$ & $11(6.5)$ & 0.33 \\
\hline \multicolumn{4}{|l|}{ Investigations } \\
\hline Median albumin (25th-75th IQR) & $32(27-37.2)$ & $34(28-40)$ & 0.076 \\
\hline
\end{tabular}

Table 6 Comparison of NTM lung disease characteristics between patients with 1 NTM species detected and patients with more than 1 NTM species detected

\begin{tabular}{|c|c|c|c|c|}
\hline Characteristics & 1 species $(N=246)$ & $\geq 2$ species $(N=106)$ & $P$ value & OR $(95 \% \mathrm{Cl})$ \\
\hline Male (\%) & $123(50)$ & $59(55.7)$ & 0.33 & \\
\hline Age $\geq 65$ years & $136(55.3)$ & $72(67.9)$ & $0.027^{*}$ & $1.7(1.1-2.8)$ \\
\hline $\begin{array}{l}\text { Median BMI } \\
\text { (25th-75th IQR) }\end{array}$ & $19.1(16.4-21.7)$ & $18.1(15.3-21.4)$ & 0.14 & \\
\hline \multicolumn{5}{|c|}{ Coexisting illnesses No. (\%) } \\
\hline HIV & $11(4.5)$ & $2(1.9)$ & 0.36 & \\
\hline $\mathrm{IHD}$ & $28(11.4)$ & $14(13.2)$ & 0.63 & \\
\hline Neoplastic disease & $73(29.7)$ & $23(21.7)$ & 0.12 & \\
\hline Diabetes mellitus & $28(11.4)$ & $15(14.2)$ & 0.47 & \\
\hline COPD & $25(10.2)$ & $21(19.8)$ & $0.013^{*}$ & $2.2(1.2-4.1)$ \\
\hline Bronchiectasis & $87(35.4)$ & $41(38.7)$ & 0.55 & \\
\hline TB history & $67(27.2)$ & $30(28.3)$ & 0.84 & \\
\hline \multicolumn{5}{|c|}{ Clinical symptoms No. (\%) } \\
\hline Cough & $181(73.6)$ & $80(75.5)$ & 0.71 & \\
\hline Phlegm & $110(44.7)$ & $51(48.1)$ & 0.56 & \\
\hline Haemoptysis & $76(30.9)$ & $38(35.8)$ & 0.36 & \\
\hline Weight loss & $50(20.3)$ & $21(19.8)$ & 0.91 & \\
\hline Chest pain & $21(8.6)$ & $7(6.6)$ & 0.53 & \\
\hline
\end{tabular}

Note: The data was presented as number (\%) unless otherwise specified. Univariate analysis was performed to assess the difference in observed variables between male and female patients with NTM diseases 
pulmonary NTM infections as approximately half of the cases with single NTM isolate from sputum or had no characteristic radiological findings were excluded from the analysis based on ATS/IDSA guideline.

\section{Conclusions}

About half of the patients in Singapore with NTM isolates met ATS/IDAS criteria of NTM diseases with highest prevalence of pulmonary NTM disease. Of the 16 NTM species (group) detected in this study, M. abscessus-chelonae group was the most frequently isolated and most involved in pulmonary NTM diseases. The patients with pulmonary NTM disease were characterized with advanced age, having history of TB and other chronic illnesses such as malignant diseases and structural lung diseases. Male patients were more associated with COPD, whereas female patients more often had bronchiectasis. Increasing age and COPD were associated with multiple NTM species detection per patient.

\section{Abbreviations \\ AFB: Acid- Fast Bacilli; ATS/IDSA: American Thoracic Society/Infectious Disease Society of America; BAL: Bronchoalveolar lavage; BMI: Body-mass index; Cl: Confidence interval; COPD: Chronic obstructive pulmonary disease; CTBL: Central Tuberculosis Laboratory; CXR: Chest X-ray; DM: Diabetes mellitus; ETTA: Endotracheal tube aspirate; HRCT: High resolution computed tomography; IHD: Ischemic heart disease; IQR: Interquartile range; MAC: $M$. avium complex; NTM: Non-tuberculous mycobacteria; OR: Odds ratio; SGH: Singapore General Hospital; TB: Tuberculosis; TNFa: Tumour necrosis factor alpha}

\section{Acknowledgements}

The authors are thankful for senior statistician Joshua Wong's help in data analysis.

\section{Funding}

This study was not funded.

\section{Availability of data and materials}

The summary data supporting the manuscript are included within the article. The raw data are not available due to Singapore Personal Data Protection Act (PDPA). We need to seek the approval of our institution (Singapore General Hospital) to release the raw data should there be a request from the public.

\section{Authors' contributions}

ZZ, TYE and SLH contributed to the design of the project. TYE and SLH performed laboratory data extraction and set up patient cohort. ZZ and BC conducted clinical data extraction and data analysis. All authors read and approved the final manuscript. The first author ZZ was a former employee of Singapore General Hospital during the study period.

\section{Ethical approval}

Ethical approval and waiver of informed consent was approved by the Centralized Institutional Review Boards of SingHealth Authority of Singapore (2015/2020).

\section{Consent for publication}

Not applicable.

\section{Competing interests}

All authors declared no competing interest associated with this study.

\section{Publisher's Note}

Springer Nature remains neutral with regard to jurisdictional claims in published maps and institutional affiliations.

\section{Author details}

'Department of Epidemiology, Medical Board, Singapore General Hospital, Singapore, Singapore. ${ }^{2}$ Department of Clinical Epidemiology, Office of Clinical Epidemiology, Analytics, and kNowledge (OCEAN), Tan Tock Seng Hospital, Singapore, Singapore. ${ }^{3}$ Department of Infectious Disease, Singapore General Hospital, Singapore, Singapore. ${ }^{4}$ Department of Microbiology,

Singapore General Hospital, Singapore, Singapore.

Received: 16 October 2018 Accepted: 15 March 2019

Published online: 17 May 2019

\section{References}

1. Johnson MM, Odell JA. Nontuberculous mycobacterial pulmonary infections. J Thorac Dis. 2014;6(3):210-20.

2. Fordham von Reyn C, Arbeit RD, Tosteson AN, Ristola MA, Barber TW, Waddell $R$, et al. The international epidemiology of disseminated Mycobacterium avium complex infection in AIDS. International MAC Study Group. Aids. 1996:10(9):1025-32.

3. von Reyn CF, Waddell RD, Eaton T, Arbeit RD, Maslow JN, Barber TW, et al. Isolation of Mycobacterium avium complex from water in the United States, Finland, Zaire, and Kenya. J Clin Microbiol. 1993;31(12):3227-30.

4. Vaerewijck MJ, Huys G, Palomino JC, Swings J, Portaels F. Mycobacteria in drinking water distribution systems: ecology and significance for human health. FEMS Microbiol Rev. 2005:29(5):911-34

5. Moriguchi S, Kita S, Yabuki Y, Inagaki R, Izumi H, Sasaki Y, et al. Reduced CaM kinase II and CaM kinase IV activities underlie cognitive deficits in NCKX2 heterozygous mice. Mol Neurobiol. 2018;55(5):3889-900.

6. Chan ED, Iseman MD. Underlying host risk factors for nontuberculous mycobacterial lung disease. Semin Respir Crit Care Med. 2013;34(1):110-23.

7. Winthrop KL, Baxter R, Liu L, Varley CD, Curtis JR, Baddley JW, et al. Mycobacterial diseases and antitumour necrosis factor therapy in USA. Ann Rheum Dis. 2013;72(1):37-42.

8. Brode SK, Jamieson FB, Ng R, Campitelli MA, Kwong JC, Paterson JM, et al. Increased risk of mycobacterial infections associated with anti-rheumatic medications. Thorax. 2015;70(7):677-82.

9. Andrejak C, Nielsen R, Thomsen VO, Duhaut P, Sorensen HT, Thomsen RW Chronic respiratory disease, inhaled corticosteroids and risk of nontuberculous mycobacteriosis. Thorax. 2013;68(3):256-62.

10. Koh WJ, Lee JH, Kwon YS, Lee KS, Suh GY, Chung MP, et al. Prevalence of gastroesophageal reflux disease in patients with nontuberculous mycobacterial lung disease. Chest. 2007;131(6):1825-30.

11. Chan ED, Iseman MD. Slender, older women appear to be more susceptible to nontuberculous mycobacterial lung disease. Gend Med. 2010;7(1):5-18.

12. Winthrop KL, Varley CD, Ory J, Cassidy PM, Hedberg K. Pulmonary disease associated with nontuberculous mycobacteria, Oregon, USA. Emerg Infect Dis. 2011;17(9):1760-1.

13. Falkinham JO 3rd. Ecology of nontuberculous mycobacteria--where do human infections come from? Semin Respir Crit Care Med. 2013:34(1):95-102.

14. Adjemian J, Olivier KN, Seitz AE, Holland SM, Prevots DR. Prevalence of nontuberculous mycobacterial lung disease in U.S. Medicare beneficiaries. Am J Respir Crit Care Med. 2012;185(8):881-6.

15. Diagnosis and treatment of disease caused by nontuberculous mycobacteria. This official statement of the American Thoracic Society was approved by the Board of Directors, March 1997. Medical Section of the American Lung Association. Am J Respir Crit Care Med. 1997;156(2 Pt 2):S1-25.

16. Management of opportunist mycobacterial infections: Joint Tuberculosis Committee Guidelines 1999. Subcommittee of the Joint Tuberculosis Committee of the British Thoracic Society. Thorax. 2000:55(3):210-8.

17. Prevots DR, Shaw PA, Strickland D, Jackson LA, Raebel MA, Blosky MA, et al. Nontuberculous mycobacterial lung disease prevalence at four integrated health care delivery systems. Am J Respir Crit Care Med. 2010;182(7):970-6.

18. Strollo SE, Adjemian J, Adjemian MK, Prevots DR. The burden of pulmonary nontuberculous mycobacterial disease in the United States. Ann Am Thorac Soc. 2015;12(10):1458-64.

19. Marras TK, Mendelson D, Marchand-Austin A, May K, Jamieson FB. Pulmonary nontuberculous mycobacterial disease, Ontario, Canada, 19982010. Emerg Infect Dis. 2013;19(11):1889-91.

20. Koh WJ, Kwon OJ, Jeon K, Kim TS, Lee KS, Park YK, et al. Clinical significance of nontuberculous mycobacteria isolated from respiratory specimens in Korea. Chest. 2006;129(2):341-8. 
21. Okumura M, Iwai K, Ogata H, Ueyama M, Kubota M, Aoki M, et al. Clinical factors on cavitary and nodular bronchiectatic types in pulmonary Mycobacterium avium complex disease. Intern Med. 2008;47(16):1465-72.

22. Lai CC, Tan CK, Chou CH, Hsu HL, Liao CH, Huang YT, et al. Increasing incidence of nontuberculous mycobacteria, Taiwan, 2000-2008. Emerg Infect Dis. 2010;16(2):294-6.

23. Kim N, Yi J, Chang CL. Recovery rates of non-tuberculous mycobacteria from clinical specimens are increasing in Korean tertiary-care hospitals. J Korean Med Sci. 2017;32(8):1263-7.

24. Kee SJ, Suh SP. Increasing burden of nontuberculous mycobacteria in Korea. J Korean Med Sci. 2017;32(8):1215-6.

25. Namkoong H, Kurashima A, Morimoto K, Hoshino Y, Hasegawa N, Ato M, et al. Epidemiology of pulmonary nontuberculous mycobacterial disease, Japan(1). Emerg Infect Dis. 2016;22(6):1116-7.

26. Huang $\mathrm{HL}$, Cheng MH, Lu PL, Shu CC, Wang JY, Wang JT, et al. Epidemiology and predictors of NTM pulmonary infection in Taiwan - a retrospective, Five-Year Multicenter Study. Sci Rep. 2017;7(1):16300.

27. Population trends. https://www.singstat.gov.sg/-/media/files/publications/ population/population2017.pdf. Cited 10 Sept 2018.

28. Tuberculosis. https://www.moh.gov.sg/diseases-updates/tuberculosis. Cited 10 Sept 2018.

29. Eckburg PB, Buadu EO, Stark P, Sarinas PS, Chitkara RK, Kuschner WG. Clinical and chest radiographic findings among persons with sputum culture positive for Mycobacterium gordonae: a review of 19 cases. Chest. 2000;117(1):96-102.

30. Wolinsky E. Nontuberculous mycobacteria and associated diseases. Am Rev Respir Dis. 1979;119(1):107-59.

31. Choudhri S, Manfreda J, Wolfe J, Parker S, Long R. Clinical significance of nontuberculous mycobacteria isolates in a Canadian tertiary care center. Clin Infect Dis. 1995;21(1):128-33.

32. Griffith DE, Aksamit T, Brown-Elliott BA, Catanzaro A, Daley C, Gordin F, et al. An official ATS/IDSA statement: diagnosis, treatment, and prevention of nontuberculous mycobacterial diseases. Am J Respir Crit Care Med. 2007; 175(4):367-416.

33. Hosker HS, Lam CW, Ng TK, Ma HK, Chan SL. The prevalence and clinical significance of pulmonary infection due to non-tuberculous mycobacteria in Hong Kong. Respir Med. 1995;89(1):3-8.

34. Winthrop KL, McNelley E, Kendall B, Marshall-Olson A, Morris C, Cassidy M, et al. Pulmonary nontuberculous mycobacterial disease prevalence and clinical features: an emerging public health disease. Am J Respir Crit Care Med. 2010;182(7):977-82

35. O'Brien RJ, Geiter LJ, Snider DE Jr. The epidemiology of nontuberculous mycobacterial diseases in the United States. Results from a national survey. Am Rev Respir Dis. 1987;135(5):1007-14.

36. Cassidy PM, Hedberg K, Saulson A, McNelly E, Winthrop KL. Nontuberculous mycobacterial disease prevalence and risk factors: a changing epidemiology. Clin Infect Dis. 2009;49(12):e124-9.

37. Prince DS, Peterson DD, Steiner RM, Gottlieb JE, Scott R, Israel HL, et al. Infection with Mycobacterium avium complex in patients without predisposing conditions. N Engl J Med. 1989;321(13):863-8.

38. Tsukamura M, Kita N, Shimoide H, Arakawa H, Kuze A. Studies on the epidemiology of nontuberculous mycobacteriosis in Japan. Am Rev Respir Dis. 1988;137(6):1280-4.

39. Koh WJ, Kwon OJ, Lee KS. Diagnosis and treatment of nontuberculous mycobacterial pulmonary diseases: a Korean perspective. J Korean Med Sci. 2005;20(6):913-25.

40. Brode SK, Marchand-Austin A, Jamieson FB, Marras TK. Pulmonary versus nonpulmonary nontuberculous mycobacteria, Ontario, Canada. Emerg Infect Dis. 2017;23(11):1898-901.

41. Lim AYH, Chotirmall SH, Fok ETK, Verma A, De PP, Goh SK, et al. Profiling nontuberculous mycobacteria in an Asian setting: characteristics and clinical outcomes of hospitalized patients in Singapore. BMC Pulm Med. 2018;18(1):85.

42. Nagano H, Kinjo T, Nei Y, Yamashiro S, Fujita J, Kishaba T. Causative species of nontuberculous mycobacterial lung disease and comparative investigation on clinical features of Mycobacterium abscessus complex disease: a retrospective analysis for two major hospitals in a subtropical region of Japan. PLoS One. 2017;12(10):e0186826.

43. Wallace RJ Jr, Dukart G, Brown-Elliott BA, Griffith DE, Scerpella EG, Marshall B. Clinical experience in 52 patients with tigecycline-containing regimens for salvage treatment of Mycobacterium abscessus and Mycobacterium chelonae infections. J Antimicrob Chemother. 2014:69(7):1945-53.
44. Lee MR, Sheng WH, Hung CC, Yu CJ, Lee LN, Hsueh PR. Mycobacterium abscessus complex infections in humans. Emerg Infect Dis. 2015;21(9):1638-46.

45. Woods GL, Brown-Elliott B, Desmond E, Hall GS, Heifets L, Pfyffer GE, et al. Susceptibility testing of mycobacteria, nocardiae, and other aerobic actinomycetes; 2003. p. 18-23.

46. Park S, Suh GY, Chung MP, Kim H, Kwon OJ, Lee KS, et al. Clinical significance of Mycobacterium fortuitum isolated from respiratory specimens. Respir Med. 2008;102(3):437-42.

47. Charles L, Daley DEG. In: Nadel's M, editor. Nontuberculous Mycobacterial Infections. 6th ed; 2016

48. Okamori S, Asakura T, Nishimura T, Tamizu E, Ishii M, Yoshida M, et al. Natural history of Mycobacterium fortuitum pulmonary infection presenting with migratory infiltrates: a case report with microbiological analysis. BMC Infect Dis. 2018:18(1):1.

49. Lessing MP, Walker MM. Fatal pulmonary infection due to Mycobacterium fortuitum. J Clin Pathol. 1993:46(3):271-2.

50. Agheli A, Tehranirad M, Cofsky R. An unusual presentation of mycobacterium fortuitum: massive isolated empyema in a patient with HIV. MedGenMed. 2006;8(2):90.

51. Hojo M, likura M, Hirano S, Sugiyama H, Kobayashi N, Kudo K. Increased risk of nontuberculous mycobacterial infection in asthmatic patients using longterm inhaled corticosteroid therapy. Respirology. 2012;17(1):185-90.

52. Fritscher LG, Marras TK, Bradi AC, Fritscher CC, Balter MS, Chapman KR. Nontuberculous mycobacterial infection as a cause of difficult-to-control asthma: a case-control study. Chest. 2011;139(1):23-7.

53. Char A, Hopkinson NS, Hansell DM, Nicholson AG, Shaw EC, Clark SJ, et al. Evidence of mycobacterial disease in COPD patients with lung volume reduction surgery; the importance of histological assessment of specimens: a cohort study. BMC Pulm Med. 2014;14:124

54. Tanaka E, Amitani R, Niimi A, Suzuki K, Murayama T, Kuze F. Yield of computed tomography and bronchoscopy for the diagnosis of Mycobacterium avium complex pulmonary disease. Am J Respir Crit Care Med. 1997;155(6):2041-6

55. Ramirez J, Aliberti S, Mirsaeidi M, Peyrani P, Filardo G, Amir A, et al. Acute myocardial infarction in hospitalized patients with community-acquired pneumonia. Clin Infect Dis. 2008:47(2):182-7.

56. Maiz L, Giron R, Olveira C, Vendrell M, Nieto R, Martinez-Garcia MA. Prevalence and factors associated with nontuberculous mycobacteria in non-cystic fibrosis bronchiectasis: a multicenter observational study. BMC Infect Dis. 2016;16(1):437.

57. Thomsen $\mathrm{VO}$, Andersen $\mathrm{AB}$, Miorner $\mathrm{H}$. Incidence and clinical significance of non-tuberculous mycobacteria isolated from clinical specimens during a $2-y$ nationwide survey. Scand J Infect Dis. 2002;34(9):648-53.

58. van Ingen J, Bendien SA, de Lange WC, Hoefsloot W, Dekhuijzen PN, Boeree $\mathrm{MJ}$, et al. Clinical relevance of non-tuberculous mycobacteria isolated in the Nijmegen-Arnhem region, The Netherlands. Thorax. 2009;64(6):502-6.

59. Simons S, van Ingen J, Hsueh PR, Van Hung N, Dekhuijzen PN, Boeree MJ, et al. Nontuberculous mycobacteria in respiratory tract infections, eastern Asia. Emerg Infect Dis. 2011;17(3):343-9.

60. Griffith DE, Girard WM, Wallace RJ Jr. Clinical features of pulmonary disease caused by rapidly growing mycobacteria. An analysis of 154 patients. Am Rev Respir Dis. 1993;147(5):1271-8.

61. Lim HJ, Park CM, Park YS, Lee J, Lee SM, Yang SC, et al. Isolation of multiple nontuberculous mycobacteria species in the same patients. Int J Infect Dis. 2011;15(11):e795-8.

62. Wallace RJ Jr, Zhang Y, Brown BA, Dawson D, Murphy DT, Wilson R, et al. Polyclonal Mycobacterium avium complex infections in patients with nodular bronchiectasis. Am J Respir Crit Care Med. 1998:158(4):1235-44.

63. Lee JS, Lee JH, Yoon SH, Kim TS, Seong MW, Han SK, et al. Implication of species change of nontuberculous mycobacteria during or after treatment. BMC Pulm Med. 2017;17(1):213. 